Int. J. Electrochem. Sci., 11 (2016) $4560-4585$

\title{
Modeling the Effect of Piperazine on Carbon Steel Corrosion Rate in Carbonated Activated MDEA Solutions
}

\author{
Lubna Ghalib ${ }^{1,2}$, Brahim Si Ali $^{1, *}$, Shaukat Mazari ${ }^{1}$, Wan Mohd Ashri $^{1}$, Idris Mohamed Saeed ${ }^{1}$ \\ ${ }^{1}$ Department of Chemical Engineering, University of Malaya, 50603 Kuala Lumpur, Malaysia \\ ${ }^{2}$ Department of Material Engineering, University of Al-Mustansiriyah, 10052 Baghdad, Iraq \\ *E-mail: brahim@um.edu.my
}

doi: $10.20964 / 2016.06 .44$

Received: 24 December 2015 / Accepted: 3 April 2016 / Published: 4 May 2016

\begin{abstract}
A comprehensive model is developed for simulating the rate of corrosion of carbon steel in carbonated aqueous activated MDEA (Methyl-di-ethanolamine) solutions. The model includes VLE (Vapor Liquid Equilibrium) and the electrochemical behavior of amine systems. The VLE model is used to predict the speciation of aqueous carbonated MDEA-PZ solutions and their concentrations, activity coefficients, and transport properties. The electrochemical model simulates partial oxidation and reduction processes on the surface of carbon steel. The model was capable to predict the effect of PZ (piperazine) concentration on the carbon steel corrosion rate, for carbonated solutions of MDEA/PZ blends. The model is executed in a Matlab program that simulates the effect of process operating conditions such as solution temperature, $\mathrm{CO}_{2}$ loading, solution $\mathrm{pH}$, total amine concentration, and $\mathrm{PZ}$ concentration on carbon steel corrosion rates. Results of speciation and corrosion models are in good agreement with the experimental findings.
\end{abstract}

Keywords: $\mathrm{CO}_{2}$ capture, $\mathrm{CO}_{2}$ corrosion, Methyl-di-ethanolamine, Piperazine, Carbon steel, Polarization curve.

\section{$\underline{\text { FULL TEXT }}$}

(C) 2016 The Authors. Published by ESG (www.electrochemsci.org). This article is an open access article distributed under the terms and conditions of the Creative Commons Attribution license (http://creativecommons.org/licenses/by/4.0/). 